\title{
Major depressive disorder and its association with adherence to antiretroviral therapy and quality of life: cross-sectional survey of people living with HIV/AIDS in Northwest Ethiopia
}

\author{
${\text { Biksegn } \text { Asrat }^{1 *} \text { (D) Crick Lund }}^{1,2}$, Fentie Ambaw ${ }^{3,4}$, Emily Claire Garman ${ }^{1}$ and Marguerite Schneider ${ }^{1}$
}

\begin{abstract}
Background: Major depression is believed to affect treatment adherence and overall quality of life (QoL) of people living with HIV/AIDS (PLWHA). Comorbid major depression contributes to a two-fold higher risk of mortality among PLWHA. Understanding the relationships of major depression, adherence to antiretroviral therapy (ART) and QoL is important to identify areas for intervention. The aim of this study is to examine relationship of major depressive disorder (MDD) and adherence to ART with QoL, and to investigate socio-demographic and clinical factors associated with MDD, adherence and QoL among PLWHA in Northwest Ethiopia.
\end{abstract}

Method: A cross-sectional study was conducted in the ART clinic of Felege-Hiwot referral hospital in Northwest Ethiopia from July to October 2019. Adult PLWHA were selected using a systematic random sampling technique. Data were collected using interview administered questionnaires and chart reviews. Mini International Neuropsychiatric Interview and WHOQOL-HIV-BREF-Eth instruments were used to measure MDD and QoL respectively. Adherence to ART was assessed using pill count data from patients' adherence monitoring chart. Univariate and multivariate Poisson regressions were used to assess associations of socio-demographic and clinical factors with MDD and adherence to ART. A multivariate linear regression was used to examine the associations of both MDD and adherence with overall QoL.

Result: Of the total of 393 invited participants, 391 (99.5\%) completed the interviews. MDD was negatively associated with overall QoL: participants with MDD had a lower QoL score of 0.17 points compared to those with no MDD. MDD was associated with reduced adherence to ART when functional disability was controlled $(R R=1.43$; $95 \% \mathrm{Cl}=1.05,1.96 ; p=0.025)$. However, there was no statistical association between adherence to ART and overall QoL. Functional disability was associated with both $\mathrm{MDD}(\mathrm{RR}=5.07 ; 95 \% \mathrm{Cl}=3.27,7.86 ; p<0.001)$ and overall $\mathrm{QoL}$ $(\beta=0.29 ; 95 \% \mathrm{Cl}=0.21,0.36 ; \mathrm{p}<0.001)$.

(Continued on next page)

* Correspondence: asrbik001@myuct.ac.za

'Alan J Flisher Centre for Public Mental Health, Department of Psychiatry and Mental Health, University of Cape Town, Cape Town, South Africa

Full list of author information is available at the end of the article

(c) The Author(s). 2020 Open Access This article is licensed under a Creative Commons Attribution 4.0 International License, which permits use, sharing, adaptation, distribution and reproduction in any medium or format, as long as you give appropriate credit to the original author(s) and the source, provide a link to the Creative Commons licence, and indicate if changes were made. The images or other third party material in this article are included in the article's Creative Commons licence, unless indicated otherwise in a credit line to the material. If material is not included in the article's Creative Commons licence and your intended use is not permitted by statutory regulation or exceeds the permitted use, you will need to obtain permission directly from the copyright holder. To view a copy of this licence, visit http://creativecommons.org/licenses/by/4.0/ The Creative Commons Public Domain Dedication waiver (http://creativecommons.org/publicdomain/zero/1.0/) applies to the data made available in this article, unless otherwise stated in a credit line to the data. 
(Continued from previous page)

Conclusion: The relationship between MDD and QoL indicates the need for feasible, acceptable and evidencebased mental health interventions to reduce depression and improve overall QoL of PLWHA. We recommend future studies investigate causal relationships of MDD, adherence to ART and QoL of PLWHA to better understand priority areas for intervention.

Keywords: Major depressive disorder, HIV, Adherence to ART, Quality of life, Ethiopia

\section{Background}

Comorbid major depression affects the clinical outcomes of HIV/AIDS [1-3] and contributes to a two-fold higher risk of mortality [4]. Major depression has been one of the challenges of the 90-90-90 Joint United Nations Program on HIV/AIDS (UNAIDS) [4] that aimed to end the epidemic of HIV/AIDS in the world [5]. The subSaharan African (SSA) countries have been lagging far behind the target and comorbid major depression remains one of the challenges that has affected engagement with HIV care, leading to early loss to treatment and low viral suppression $[4,6]$.

Major depression is the most common mental disorder among people living with HIV/AIDS (PLWHA) and is estimated to be two to three times higher in PLWHA than in general population [4, 7-9]. However, prevalence reports are markedly variable across studies due partially to the use of different measurement approaches. A systematic review of studies from SSA found a range of 9 to $32 \%$ prevalence of probable depression [10]. A metaanalysis of studies from East Africa indicated a 38\% pooled prevalence of probable depression [11]. A systematic review of studies from Ethiopia reported a $37 \%$ pooled prevalence of probable depression among PLWHA [12] which was much higher compared to the $11 \%$ pooled prevalence in the general population [13].

Major depression is prevalent in PLWHA due to their vulnerability to several factors. These factors can be classified as: 1) psychosocial factors such as HIV related stigma, disability and poverty [14-16]; 2) biological factors, such as structural and functional changes in the brain due to HIV infection (alteration in hypothalamic-pituitary-thyroid pathway) [9, 17-19] and due to chronic immune activation [2]; and 3) other comorbid conditions, including pre-existing comorbid illnesses other than HIV/AIDS which may increase risk of depression [18].

Major depression is believed to be one of the factors that affects adherence to ART although findings are inconclusive [20-22]. While many studies support the strong association, two systematic reviews did not find an independent relationship between major depression and adherence to ART $[23,24]$. There are assumptions that cognitive impairment due to major depression, such as forgetfulness, poor concentration, impairment in memory, low executive functioning and difficulties with learning new behavior, may contribute to non-adherence to ART [25]. In addition, affective symptoms of major depression such as loss of interest, poor motivation, hopelessness and suicidality have also been reported to affect adherence to ART [4, 6].

Major depression is also an important determinant of Quality of Life (QoL) for PLWHA [6, 26-28]. QoL is a broad concept that includes several domains of functioning, namely physical, psychological, independence, social, environmental and spiritual functioning and can be affected by a variety of life circumstances [29-31]. However, the impact of major depression on poorer QoL outcomes seems to be high for PLWHA [32].

Although the pathways are not fully understood, major depression is reported to affect overall QoL of PLWHA either directly $[3,17,20,33]$ and/or indirectly by affecting adherence to antiretroviral therapy (ART) [19, 34]. Studies in HIV populations have indicated that major depression can affect several domains of QoL directly. For example, the effect of major depression on psychological and social functioning has been reported [35-37]. There are also studies that have shown a strong association between major depression and overall QoL, but the direction of association is unclear [32, 38].

Biological studies support the association of major depression with poor physical health and poor immune functioning $[19,39,40]$. For example, major depression has been reported to cause immunosuppression by altering the function of lymphocytes and decreasing natural killer cells [18]. The association of major depression with decreased CD4 cells, altered immune response and increased release of proinflammatory cytokines has been commonly reported $[9,19]$. This may suggest that major depression can have a direct role in the physical deterioration and progress to advanced disease stage of PLWHA by interfering with immune functioning. Therefore, aiming to achieve overall improvement in QoL with the use of ART alone may not be successful without addressing major depression in PLWHA particularly in SSA $[3,19,41]$.

In Ethiopia, several studies have examined prevalence of probable depression using screening tools [12]. However, diagnosis of major depression is important to develop treatment protocols, training manuals and to 
revise patient teaching guidelines. Furthermore, understanding relationships of major depression, adherence and QoL is important to design acceptable, feasible and evidence-based interventions for PLWHA. This study was a baseline survey used to identify and recruit cases with major depressive disorder (MDD) for a group interpersonal therapy intervention for PLWHA. This paper presents 1) the prevalence and associated factors of major depressive disorder (MDD), 2) the prevalence and associated factors of adherence to ART, 3) the factors associated with QoL, and 4) the associations of MDD and adherence to ART with overall QoL among PLWHA in Northwest Ethiopia.

\section{Method}

\section{Setting and participants}

This cross-sectional study was conducted in the ART clinic of Felege-Hiwot referral hospital (FHRH) in Northwest Ethiopia from 8th July to 7th October 2019. FHRH is one of the busiest hospitals in Northwest Ethiopia as described elsewhere [42] and serves a population of more than 7 million people. More than 3508 PLWHA had received ART treatment at the ART clinic over the 3 months preceding the data collection period, 2948 of which were adults 18 years and above. Sample size was calculated using the Select Statistical Services computer program using the following assumptions: a) a population proportion of $37 \%$ prevalence of depression which was taken from previous meta-analysis study findings done in people living with HIV/AIDS (PLWHA) in Ethiopia [1]. b) a $5 \%$ margin of error at $95 \%$ confidence interval. The sample size was estimated to be 357 . Then we have added a $10 \%$ for the non-response rate which provided a total sample size of 392.7 (approximated to 393).

Participants were recruited using a systematic random sampling technique with an interval of seven. Patients medical cards were used to select every seventh client among those who were waiting for their ART follow-up at the ART clinic. Inclusion criteria were 18 years old and above, and able to provide informed consent. Exclusion criteria were being too ill to communicate or with a major physical illness, or emotional problems as result of an organic cause. In addition, those participants who diagnosed with cognitive deficits by clinicians were excluded from the study.

\section{Procedure}

A research assistant approached every eligible client to explain the purpose of study, to ask for their willingness to be included in the study and to clarify the information in the informed consent sheet. Participants who signed consent forms were interviewed by trained data collectors in a private room in the ART clinic. The interviews were conducted in the local language (Amharic) and responses noted on paper questionnaires with no names and just a participant ID. The signed consent forms and completed questionnaires were kept in a locked file.

Data were collected using interview administered questionnaires and patient chart reviews. Sociodemographic, MDD, adherence, QoL, functioning and social support information was collected using an interviewer administered questionnaire. HIV related clinical information such as CD4 count, duration of ART treatment and ART regimen was collected from the patient charts. Field workers, including data collectors and supervisors, were trained for three days on participant selection, informed consent administration, data collection techniques and data handling.

Study participants who fulfilled the criteria for MDD or with suicidal idea were referred to group interpersonal therapy counselors for further evaluation and intervention. The counselors evaluated the severity and treatment need of each referred study participant and they intervened based on the given standard operating procedure. Those study participants who were severely sick were referred to the psychiatric clinic for advanced care and treatment.

\section{Measurements \\ MDD}

The Mini International Neuropsychiatric Interview (MINI-7.0.2) a structured diagnostic assessment scale, was used to assess MDD [43]. The MINI-7.0.2 allows DSM-5 diagnosis and has been widely used as a gold standard measure of MDD [43, 44]. The MINI has been adapted to the Ethiopian context for use by nonspecialized health professionals to detect MDD [45]. The diagnosis of MDD was made after organic causes were ruled out using the exclusion items in the MINI.

\section{Quality of life (QoL)}

The WHOQOL-HIV-BREF-Eth, that was adapted from the World Health Organization quality of life module and validated in the local language (Amharic) [46], was used to measure QoL in this study. The WHOQOLHIV-BREF-Eth was validated for use in PLWHA in Ethiopia and has been used in several studies in HIV populations $[29,32,38]$. The validation shows that it has an excellent internal consistency with Cronbach alpha of 0.93 . The instrument included two general items and six domains that give a total of 27 items. Study participants were asked to rate their subjective general wellbeing from 1 to 5 where low scores indicate low general wellbeing as perceived by study participants. Mean QoL score was calculated by dividing the sum scores of QoL by 27. Mean scores of each domain of QoL (physical, 
psychological, independence, social, environmental and spiritual) were also calculated independently.

\section{Adherence to ART}

We assessed adherence to ART using the pill count data, captured from patients' re-fill chart and used for the purpose of clinical monitoring, together with clinicians' report of skipped doses. Pill count is a valid method used to measure adherence to ART and has been used by several studies in resource limited settings [47, 48]. Upon examination of the frequencies and distribution of our data, we found that the data were skewed towards high adherence. Therefore, we narrowly defined high adherence as taking all doses of ART medications as prescribed by the clinician since the last appointment and suboptimal adherence was defined as skipping one or more doses of the prescribed medications.

\section{Functional disability}

The World Health Organization Disability Assessment Schedule (WHODAS-12) was used to measure functional disability. The WHODAS-12 instrument was high in acceptability, understandability and relevance to the WHODAS-36 instrument for the Ethiopian context [49]. Each item of the WHODAS-12 has Likert scale response options (No Difficulty $=0$, Mild Difficulty $=1$, Moderate Difficulty $=2$, Severe Difficulty $=3$, Extreme Difficulty/ 'Cannot Do' $=4$ ). The scores of each item were summed and total scores can range from minimum of 0 to maximum of 48. In this study, functional disability was defined as a score of 36 or higher (i.e. having severe or extreme difficulty).

\section{Perceived social support (PSS)}

The Multidimensional Scale of Perceived Social Support (MSPSS) was used to evaluate perceived social support. The MSPSS has been adapted and validated in different settings across the world including in Africa [50-52]. The instrument has been shown to be reliable and valid for use in African cultures, for instance in Malawi [53] and Uganda [54]. The instrument evaluates perceived social support adequacy using three subscales: family, friends and significant others [50]. The MSPSS has 12items (each subscale has 4-items) with 7-point Likert scale response options from 1 (very strongly disagree) to 7 (very strongly agree) [50, 55]. The value of each item was summed, and mean scores were calculated. The mean scores can range from minimum of 1 to maximum of 7. In this study mean scores ranging from 1 to 3 indicate low PSS, from 3 to 5 indicate moderate PSS and 5 to 7 indicate high PSS $[55,56]$.

\section{Data analysis}

Data were entered into Epidata 4.6.0.0 [57] and analysed using SPSS statistics version 26 computer program [58]. Items of MDD, QoL, adherence to ART, PSS, functional disability and suicidality were computed to generate aggregated variables. Descriptive statistical analysis was used to summarize outcome variables, sociodemographic and clinical factors.

Univariate Poisson regression was used to identify association of each socio-demographic and clinical factor with MDD, and risk ratios are reported [59]. In multivariate Poisson regression, all factors with $p$-value $<0.2$ in the univariate Poisson regression were entered in a multivariate analysis to control for confounding factors and generate adjusted risk ratios.

Similarly, we used univariate Poisson regression to identify the association of socio-demographic and clinical variables with adherence to ART, and risk ratios are reported. All factors with $p$-value of $<0.2$ in the univariate Poisson regression were entered in a multivariate analysis to control for confounding factors and generate adjusted risk ratios.

We used linear regression to identify factors associated with the overall QoL. First, each of the sociodemographic and clinical variables were entered in a univariate model. Then, factors associated with overall QoL in the univariate analyses at a $p$-value $<0.2$ were entered in a multivariate linear regression to adjust for confounding factors. These factors were also entered in a multivariate linear regression, for each domain of QoL separately, to examine the association of sociodemographic and clinical factors with each domain of QoL.

Finally, association of MDD and adherence to ART with overall QoL was examined using a generalized linear model. All socio-demographic and clinical factors associated with overall QoL at $p$-value of $<0.05$ in the previous analysis were adjusted for in the model. An interaction analysis was also used in the model to assess interaction of MDD and adherence to ART on overall QoL.

\section{Ethics approval and consent to participate}

This study was approved by the University of Cape Town's Human Research Ethics Committee (HREC reference No. 653/2018). In addition, an approval letter was obtained from Bahir Dar University College of Medicine and Health Sciences' Ethics Committee (reference No. 007/2018) and a permission letter was obtained from the Amhara Public Health Institute (APHI). All study participants signed a written informed consent. Illiterate study participants signed by fingerprint after a witness read the written informed consent. 


\section{Results}

Socio-demographic and clinical characteristics of study participants

Of the total of 393 invited participants, 391 (99.5\%) completed the interviews. More than two-thirds (69.3\%, $n=269$ ) of the study participants were women. The mean age of participants was 38.7 years old $(\mathrm{SD}=9.1)$ ranging from 18 to 78 years old respectively. Three quarters $(74.6 \%, n=288)$ of the study participants were on first line ART treatments Table 1.

\section{Prevalence and associated factors of MDD}

The overall prevalence of MDD was $32.5 \%(n=127$; $95 \% \mathrm{CI}=28.1,37.3)$ and it was $46.3 \%(n=57)$ among illiterate, 44.4\% $(n=55)$ among unemployed, $65.4 \%(n=$ 100) among functionally disabled study participants. The prevalence of MDD in each variable is presented in Table 2.

In the univariate regression (unadjusted analysis), being divorced or widowed, illiterate, unemployed, with low PSS, and on second line ART regimen were significantly associated with MDD. Results from the multivariate Poisson regression (adjusted analysis) show that only functional disability was associated with MDD: those who had functional disability $(65.4 \%, n=100)$ had 5.07 times the risk of MDD compared to those who had no functional disability $(11 \%, n=26) \quad(95 \% \mathrm{CI}=3.27,7.86$, $p<0.001)$.

\section{Prevalence of adherence to ART and associated factors}

Overall, $81.9 \%$ of respondents $(n=289 ; 95 \% \mathrm{CI}=77.9$, 85.8) had high adherence to ART (see Table 1). MDD was associated with reduced adherence to ART when functional disability was controlled for: those who had MDD $(62.2 \%, n=74)$ had 1.43 times the risk of suboptimal adherence to ART compared to those who had no $\operatorname{MDD}(91.9 \%, n=215) \quad(95 \% \mathrm{CI}=1.05,1.96 ; p=0.025)$ (see Table 3).

\section{Factors associated with QoL}

The overall QoL mean score was $3.86(\mathrm{SD}=0.42)$ and the mean scores for physical, psychological, independence, social, environmental and spiritual domains were $4.16(\mathrm{SD}=0.56), 3.73(\mathrm{SD}=0.65), 4.02(\mathrm{SD}=0.56), 3.76$ $(\mathrm{SD}=0.60), 3.27(\mathrm{SD}=0.61)$ and $4.42(0.44)$ respectively. The multivariate linear regression shows that a higher level of education was positively associated with overall QoL: those with tertiary education had a higher QoL score of 0.34 compared to those who were illiterate $(95 \% \mathrm{CI}=0.19,0.49 ; p<0.001)$ (see Table 4$)$. Taking firstline ART treatment was positively associated with overall QoL: participants who were taking first-line ART treatment had a higher QoL score of 0.12 compared to participants who were taking second-line ART treatment
$(95 \% \mathrm{CI}=0.03,0.20 ; p<0.008)$. Similarly, taking ART for a longer duration was also positively associated with overall QoL: those who had taken ART for 6-10 years had a higher QoL score of 0.12 compared to those who had taken ART for less than 6 years $(95 \% \mathrm{CI}=0.02,0.22$; $p=0.022$ ). High PSS was positively associated with overall QoL: participants who had high PSS had a higher QoL score of 0.43 compared to those who had low PSS $(95 \% \mathrm{CI}=0.29,0.57 ; p<0.001)$. Functional disability was also associated with overall QoL: those who had no functional disability had a higher QoL score of 0.29 compared to those who had functional disability $(95 \% \mathrm{CI}=0.21,0.36 ; \mathrm{p}<0.001)$.

In addition, the adjusted linear regressions by domains of QoL show that age and employment were statistically associated with one or more domains of QoL (see Table 5). In the univariate analysis, being married or in a relationship and public employment were significantly associated with a higher QoL score.

\section{Association of MDD and adherence to ART with overall QOL}

After controlling for socio-demographic and clinical factors associated with overall QoL, results of the multivariate linear regression show that MDD was negatively associated with overall QoL: participants with MDD had a lower QoL score of 0.06 compared to those with no MDD (95\%CI $=0.89,0.99 ; p<0.047)$ (see Table 6). However, there was no statistical association between adherence to ART and overall QOL. The generalized linear model presented no interaction effect of MDD and adherence to ART on QoL scores $(95 \% \mathrm{CI}=0.94,1.07 ; \beta=$ $0.01 ; p=0.866)$.

\section{Discussion}

Unlike most of the previous studies in HIV populations in Ethiopia, this study examined the prevalence of major depression using a diagnostic instrument. We found that one third of the study participants had MDD, and that being divorced or widowed, illiterate, unemployed, with low perceived social support, and on second line ART regimen were significantly associated with MDD in univariate regressions (unadjusted analysis). MDD was strongly associated with functional disability and suboptimal adherence to ART in the multivariate regression (adjusted analysis). We also identified associations between higher overall QoL and better educational status, better PSS, functioning, taking ART for a longer duration and taking first-line ART treatments. Our study indicated that MDD was strongly associated with lower overall QoL.

More than two thirds of the study participants were women. However, there was no difference in prevalence of MDD between men and women. The reason for the 
Table 1 Socio-demographic and clinical characteristics of the study participants, Felege-Hiwot Referral Hospital (FHRH), Northwest Ethiopia ( $N=391)$

\begin{tabular}{|c|c|c|c|}
\hline \multicolumn{2}{|c|}{ Sociodemographic and clinical characteristics } & \multirow{2}{*}{$\begin{array}{l}\text { Frequency } \\
51\end{array}$} & \multirow{2}{*}{$\begin{array}{l}\text { Percen } \\
13.2\end{array}$} \\
\hline Age in years & $18-29$ & & \\
\hline & $30-39$ & 161 & 41.8 \\
\hline & $40-49$ & 119 & 30.9 \\
\hline & $50+$ & 54 & 14.0 \\
\hline \multirow[t]{2}{*}{ Gender } & Male & 119 & 30.7 \\
\hline & Female & 269 & 69.3 \\
\hline \multirow[t]{3}{*}{ Marital status } & Single & 53 & 13.6 \\
\hline & Married/in relationship & 187 & 47.8 \\
\hline & Divorced/widowed & 151 & 38.6 \\
\hline \multirow[t]{4}{*}{ Educational status } & Illiterate & 123 & 31.5 \\
\hline & Primary education & 125 & 32.0 \\
\hline & Secondary education & 93 & 23.8 \\
\hline & Tertiary education & 50 & 12.8 \\
\hline \multirow[t]{3}{*}{ Employment } & Public servant & 84 & 21.5 \\
\hline & Self employed & 182 & 46.7 \\
\hline & None employed & 124 & 31.8 \\
\hline \multirow[t]{4}{*}{ Current CD4 count (last 6 months) } & $<200$ & 28 & 7.6 \\
\hline & 200-349 & 69 & 18.6 \\
\hline & 350-499 & 95 & 25.7 \\
\hline & $>500$ & 178 & 48.1 \\
\hline \multirow[t]{2}{*}{ Antiretroviral therapy regimen } & First-line & 288 & 74.6 \\
\hline & Second-line & 98 & 25.4 \\
\hline \multirow[t]{3}{*}{ Duration of ART treatment in years } & $1-5$ & 72 & 19.0 \\
\hline & $6-10$ & 134 & 35.4 \\
\hline & 11 and above & 175 & 45.6 \\
\hline \multirow[t]{2}{*}{ Major depressive disorder } & Yes & 127 & 32.5 \\
\hline & No & 264 & 67.5 \\
\hline \multirow[t]{2}{*}{ ART adherence } & High adherence & 289 & 81.9 \\
\hline & Low adherence & 64 & 18.1 \\
\hline
\end{tabular}

NOTE: First-line regimen is the use of first choice antiviral drugs and a switch to second-line regimen is recommended when there is treatment failure with first-line treatments

majority of the participants being women could be due to a higher prevalence of HIV/AIDS among women than men. This is supported by several reports that have shown that HIV/AIDS is more prevalent in women than men in Ethiopia [60]. Our study found that there was no difference in prevalence of MDD by age and gender which is in agreement with findings from another study reporting that MDD is prevalent in all age groups and in both genders of PLWHA [10]. Biological impact of HIV [61], stigma and poor social support [8], and low socioeconomic conditions [10] all contribute to a high prevalence of MDD among PLWHA.

In this study, there was a significant association between PSS and MDD in the univariate regression but no association between PSS and MDD in the multivariate regression. This finding is inconsistent with a systematic review of longitudinal studies that reported poorer PSS causes worse outcomes of MDD in terms of functioning and recovery [62] and with another systematic review of studies from Africa that reported presence of a strong relationship between PSS and MDD [8]. However, a systematic review of studies from high income countries [63] and another longitudinal study among adolescents from China [64] reported no relationship between level of PSS and MDD. There is conflicting global evidence on a causal relationship between PSS and MDD. Interpersonal theories of depression indicate that poor social support leads to onset of MDD [65]. In contrast, a more recent longitudinal study 
Table 2 Poisson regression: prevalence of and factors associated with major depressive disorder among people living with HIV/AIDS in Felege-Hiwot Referral Hospital $(F H R H)$, Northwest Ethiopia, $(N=391)$

\begin{tabular}{|c|c|c|c|c|c|c|c|c|}
\hline \multicolumn{2}{|l|}{ Sociodemographic and clinical factors } & \multirow{2}{*}{ 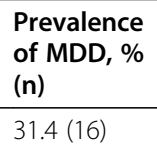 } & \multicolumn{3}{|c|}{ Unadjusted Poisson regression } & \multicolumn{3}{|c|}{ Adjusted Poisson regression } \\
\hline Age in years ${ }^{a}$ & $18-29$ & & $\begin{array}{l}\text { Risk ratio } \\
1.11\end{array}$ & $\begin{array}{l}\mathbf{9 5 \% C l} \\
0.56,2.19\end{array}$ & $\begin{array}{l}\boldsymbol{P} \text { value } \\
0.770\end{array}$ & Risk ratio & $95 \% \mathrm{Cl}$ & \\
\hline & $30-39$ & $33.5(54)$ & 1.18 & $0.69,2.04$ & 0.544 & & & \\
\hline & $40-49$ & $33.6(40)$ & 1.19 & $0.67,2.09$ & 0.555 & & & \\
\hline & $50+$ & $29.6(16)$ & Reference & Reference & & & & \\
\hline \multirow[t]{2}{*}{ Gender } & Male & $25.2(30)$ & Reference & Reference & & & & \\
\hline & Female & $36.1(97)$ & 1.47 & $0.97,2.21$ & 0.067 & 1.13 & $0.72,1.78$ & 0.600 \\
\hline \multirow[t]{3}{*}{ Marital status } & Married/in relationship & $25.7(48)$ & Reference & Reference & & Reference & Reference & \\
\hline & Single & $37.7(20)$ & 1.47 & $0.87,2.48$ & 0.148 & 1.13 & $0.65,1.96$ & 0.675 \\
\hline & Divorced/widowed & $39.1(59)$ & 1.52 & $1.04,2.23$ & 0.031 & 1.01 & $0.67,1.53$ & 0.968 \\
\hline \multirow[t]{4}{*}{ Educational status } & Illiterate & $46.3(57)$ & 2.11 & $1.11,4.02$ & 0.024 & 1.04 & $0.43,2.50$ & 0.930 \\
\hline & Primary education & $28.0(35)$ & 1.27 & $0.65,2.51$ & 0.485 & 0.90 & $0.39,2.10$ & 0.812 \\
\hline & Secondary education & $25.8(24)$ & 1.17 & $0.58,2.40$ & 0.661 & 0.83 & $0.35,1.99$ & 0.682 \\
\hline & Tertiary education & $22.0(11)$ & Reference & Reference & & Reference & & \\
\hline \multirow[t]{3}{*}{ Employment } & Public employed & $17.9(15)$ & Reference & Reference & & Reference & & \\
\hline & Self employed & $30.8(56)$ & 1.64 & $0.94,2.85$ & 0.083 & 1.40 & $0.68,2.89$ & 0.366 \\
\hline & Unemployed & $44.4(55)$ & 2.36 & $1.35,4.11$ & $<0.003$ & 1.75 & $0.84,3.63$ & 0.135 \\
\hline \multirow[t]{3}{*}{ Perceived social support } & High support & $24.3(55)$ & Reference & Reference & & Reference & Reference & \\
\hline & Moderate support & $41.9(54)$ & 1.70 & $1.17,2.46$ & $<0.005$ & 1.21 & $0.82,1.78$ & 0.337 \\
\hline & Low support & $55.6(15)$ & 2.25 & $1.28,3.97$ & $<0.005$ & 1.25 & $0.67,2.31$ & 0.481 \\
\hline \multirow[t]{2}{*}{ ART regimen } & First-line & $27.8(80)$ & Reference & Reference & & Reference & Reference & \\
\hline & Second-line & $45.9(45)$ & 1.64 & $1.14,2.36$ & $<0.008$ & 1.31 & $0.90,1.91$ & 0.157 \\
\hline \multirow[t]{2}{*}{ Functional disability } & No & $11.0(26)$ & Reference & Reference & & Reference & Reference & \\
\hline & Yes & $65.4(100)$ & 5.76 & $3.77,8.81$ & $<0.001$ & 5.07 & $3.27,7.86$ & $<0.001$ \\
\hline \multirow[t]{4}{*}{ Current CD4 count (last 6 months) ${ }^{a}$} & $<200$ & $35.7(10)$ & 0.98 & $0.51,1.91$ & 0.969 & & & \\
\hline & $200-349$ & $26.1(18)$ & 0.72 & $0.43,1.21$ & 0.215 & & & \\
\hline & $350-499$ & $28.4(27)$ & 0.78 & $0.51,1.22$ & 0.285 & & & \\
\hline & $>500$ & $36.5(65)$ & Reference & Reference & & & & \\
\hline \multirow[t]{3}{*}{ ART treatment duration in years ${ }^{a}$} & $1-5$ & $29.2(21)$ & 0.81 & $0.49,1.32$ & 0.387 & & & \\
\hline & $6-10$ & $29.1(39)$ & 0.80 & $0.54,1.19$ & 0.278 & & & \\
\hline & 11 and above & $36.4(63)$ & Reference & Reference & & & & \\
\hline
\end{tabular}

NOTE: First-line regimen is the use of first choice antiviral drugs and a switch to second-line regimen is recommended when there is treatment failure with firstline treatments. ART: antiretroviral therapy. ${ }^{a}$ variables not included in multivariate Poisson regression

presented evidence that PSS is a consequence of MDD contrary to social causation theories of depression [64], reporting that the negative views of people with MDD can make it uncomfortable for peers to provide social support. In addition, lack of social skills of people with MDD to create and maintain a relationship may result in a social avoidance state. Despite our findings, we believe that social support could be an important intervention for MDD. MDD caused by a psychosocial crisis can be effectively treated by strong social support, which helps to decrease interpersonal stress and improve interpersonal skills [65].
Our study shows that functional disability was independently associated with MDD. Functional disability prevents people with MDD from performing daily activities, leads to loss of social roles and lack of access to resources for basic needs [66]. Failure to fulfil self needs and social responsibilities can lead to onset of full blown MDD, or reciprocally MDD can lead to functional disability [67]. Furthermore, people with functional disability need more intensive social and material support due to poverty and this could aggravate pre-existing MDD [68]. 
Table 3 Poisson regression: Prevalence of and factors associated with adherence to antiretroviral therapy among people living with HIV/AIDS in Felege-Hiwot Referral Hospital, Northwest Ethiopia, ( $N=353)$

\begin{tabular}{|c|c|c|c|c|c|c|c|c|}
\hline \multirow{2}{*}{\multicolumn{2}{|c|}{ Sociodemographic and clinical factors }} & \multirow{3}{*}{$\begin{array}{l}\begin{array}{l}\text { Prevalence } \\
\text { of high } \\
\text { adherence, } \\
\% \text { (n) }\end{array} \\
79.2(38)\end{array}$} & \multirow{2}{*}{\multicolumn{3}{|c|}{ Unadjusted Poisson regression }} & \multicolumn{3}{|c|}{ Adjusted Poisson regression } \\
\hline & & & & & & & & \\
\hline Age in years $^{a}$ & $18-29$ & & $\begin{array}{l}\text { Risk ratio } \\
\text { Reference }\end{array}$ & $95 \% \mathrm{Cl}$ & $P$ value & Risk ratio & $95 \% \mathrm{Cl}$ & $P$ value \\
\hline & $30-39$ & $82.4(122)$ & 1.04 & $0.73,1.47$ & 0.845 & & & \\
\hline & $40-49$ & $81.1(86)$ & 1.02 & $0.71,1.47$ & 0.920 & & & \\
\hline & $50+$ & $84.4(38)$ & 1.06 & $0.69,1.64$ & 0.792 & & & \\
\hline \multirow[t]{2}{*}{ Gender $^{a}$} & Male & $83.3(90)$ & 1.03 & $0.80,1.32$ & 0.840 & & & \\
\hline & Female & $81.0(196)$ & Reference & & & & & \\
\hline \multirow[t]{3}{*}{ Marital status $^{a}$} & Single & $76.0(38)$ & Reference & & & & & \\
\hline & Married/in relationship & $85.7(144)$ & 1.13 & $0.79,1.61$ & 0.510 & & & \\
\hline & Divorced/widowed & $79.3(107)$ & 1.04 & $0.72,1.51$ & 0.824 & & & \\
\hline \multirow[t]{4}{*}{ Educational status $^{\text {a }}$} & Illiterate & $77.9(88)$ & Reference & & & & & \\
\hline & Primary education & $79.5(89)$ & 1.02 & $0.76,1.37$ & 0.893 & & & \\
\hline & Secondary education & $85.4(70)$ & 1.09 & $0.80,1.50$ & 0.566 & & & \\
\hline & Tertiary education & $91.3(42)$ & 1.17 & $0.81,1.69$ & 0.396 & & & \\
\hline \multirow[t]{3}{*}{ Employment $^{\mathrm{a}}$} & Public employed & $91.9(68)$ & 1.21 & $0.88,1.66$ & 0.245 & & & \\
\hline & Self employed & $81.3(135)$ & 1.07 & $0.82,1.40$ & 0.631 & & & \\
\hline & Unemployed & $75.9(85)$ & Reference & & & & & \\
\hline \multirow[t]{3}{*}{ Perceived social support ${ }^{a}$} & High support & $82.8(164)$ & 1.14 & $0.74,1.75$ & 0.552 & & & \\
\hline & Moderate support & $82.8(101)$ & 1.14 & $0.73,1.78$ & 0.568 & & & \\
\hline & Low support & $69.2(18)$ & Reference & & & & & \\
\hline \multirow[t]{2}{*}{ ART regimen ${ }^{a}$} & First-line & $84.4(217)$ & 1.13 & $0.86,1.47$ & 0.383 & & & \\
\hline & Second-line & $75.8(69)$ & Reference & & & & & \\
\hline \multirow[t]{2}{*}{ Functional disability } & No & $89.6(189)$ & 1.27 & $0.99,1.62$ & 0.052 & 1.06 & $0.79,1.41$ & 0.710 \\
\hline & Yes & $70.8(98)$ & Reference & & & Reference & & \\
\hline \multirow[t]{4}{*}{ Current CD4 count (last 6 months) ${ }^{a}$} & $<200$ & $79.2(19)$ & Reference & & & & & \\
\hline & $200-349$ & $81.3(52)$ & 1.08 & $0.70,1.68$ & 0.719 & & & \\
\hline & $350-499$ & $86.0(74)$ & 1.15 & $0.76,1.73$ & 0.512 & & & \\
\hline & $>500$ & $81.8(130)$ & 1.09 & $0.74,1.60$ & 0.658 & & & \\
\hline \multirow[t]{3}{*}{ ART treatment duration in years ${ }^{\text {a }}$} & $1-5$ & $82.3(51)$ & Reference & & & & & \\
\hline & $6-10$ & $82.4(98)$ & 1.05 & $0.76,1.45$ & 0.765 & & & \\
\hline & 11 and above & $83.1(133)$ & 1.06 & $0.78,1.44$ & 0.709 & & & \\
\hline \multirow[t]{2}{*}{ Major depressive disorder } & No & $91.9(215)$ & 1.48 & $1.14,1.92$ & 0.004 & 1.43 & $1.05,1.96$ & 0.025 \\
\hline & Yes & $62.2(74)$ & Reference & & & Reference & & \\
\hline
\end{tabular}

NOTE: First-line regimen is the use of first choice antiviral drugs and a switch to second-line regimen is recommended when there is treatment failure with firstline treatments. ${ }^{\text {a }}$ variables not included in multivariate Poisson regression; $A R T$ antiretroviral therapy

Our finding about the association of several sociodemographic and clinical factors with overall QoL is consistent with previous findings. Better educational status [69-71], being employed [72, 73], good social support [69, 72], functioning [20] and access to first line ART treatment $[71,74]$ have been identified as predictors of improved QoL. Our findings support the hypothesis that PLWHA with better education and with good physical functioning could have better income and employment opportunities to gain better QoL.

None of the socio-demographic and clinical factors showed statistical associations with adherence to ART which is inconsistent with previous findings [24]. This can be explained by challenges in measuring adherence to ART using pill count. There was also inconsistency in using specific measures across studies that may be misleading in assessing treatment adherence in HIV populations. But MDD seems an important predictor of suboptimal adherence to ART which is supported by several findings from previous studies [71, 72]. This could be due to MDD related cognitive impairment, such as memory loss and forgetfulness in taking ART medications [73-75], or due to poor motivation, hopelessness and wishing to die [4]. Our findings show the 
Table 4 Linear regression: Association of socio-demographic and clinical factors with overall quality of life among people living with HIV/AIDS in Felege-Hiwot Referral Hospital, Northwest Ethiopia, $(N=391)$

\begin{tabular}{|c|c|c|c|c|c|c|c|c|}
\hline \multirow[t]{2}{*}{ Factors } & & \multirow[t]{2}{*}{$\begin{array}{l}\text { Mean } \\
\text { (SD) }\end{array}$} & \multicolumn{3}{|c|}{ Unadjusted linear regression } & \multicolumn{3}{|c|}{$\begin{array}{l}\text { Adjusted multivariate linear } \\
\text { regression }\end{array}$} \\
\hline & & & Coefficient & $95 \% \mathrm{Cl}$ & $P$ value & Coefficient & $95 \% \mathrm{Cl}$ & $P$ value \\
\hline \multirow[t]{4}{*}{ Age in years } & $18-29$ & $3.76(0.40)$ & Reference & Reference & & Reference & Reference & \\
\hline & $30-39$ & $3.86(0.44)$ & 0.27 & $-0.26,0.80$ & 0.313 & 0.07 & $-0.04,0.19$ & 0.209 \\
\hline & $40-49$ & $3.91(0.43)$ & 0.49 & $-0.07,1.05$ & 0.087 & 0.10 & $-0.2,0.23$ & 0.102 \\
\hline & $50+$ & $3.83(0.37)$ & 0.18 & $-0.48,0.83$ & 0.601 & 0.06 & -0.08 .0 .21 & 0.371 \\
\hline \multirow[t]{2}{*}{ Gender $^{a}$} & Male & $3.90(0.39)$ & 0.23 & $-0.16,0.61$ & 0.255 & & & \\
\hline & Female & $3.84(0.44)$ & Reference & Reference & & & & \\
\hline \multirow[t]{3}{*}{ Marital status } & Single & $3.77(0.45)$ & -0.08 & $-0.65,0.48$ & 0.770 & -0.04 & $-0.16,0.08$ & 0.530 \\
\hline & Married/ in relationship & $3.93(0.39)$ & 0.57 & $0.18,0.95$ & $<0.004$ & -0.01 & $-0.08,0.08$ & 0.974 \\
\hline & Divorced/widowed & $3.79(0.45)$ & Reference & Reference & & Reference & Reference & \\
\hline \multirow[t]{4}{*}{ Educational status } & Illiterate & $3.67(0.50)$ & Reference & Reference & & Reference & Reference & \\
\hline & Primary education & $3.87(0.37)$ & 0.78 & $0.35,1.21$ & $<0.001$ & 0.13 & $0.03,0.22$ & $<0.008$ \\
\hline & Secondary education & $3.95(0.35)$ & 1.12 & $0.65,1.58$ & $<0.001$ & 0.20 & $0.09,0.31$ & $<0.001$ \\
\hline & Tertiary education & $4.09(0.31)$ & 1.69 & $1.13,2.25$ & $<0.001$ & 0.34 & $0.19,0.49$ & $<0.001$ \\
\hline \multirow[t]{3}{*}{ Employment status } & Public employed & $4.01(0.32)$ & 0.85 & $0.37,1.33$ & 0.001 & -0.07 & $-0.19,0.05$ & 0.274 \\
\hline & Self employed & $3.83(0.42)$ & 0.14 & $-0.27,0.55$ & 0.499 & 0.01 & $-0.08,0.09$ & 0.886 \\
\hline & None employed & $3.81(0.44)$ & Reference & Reference & & Reference & Reference & \\
\hline \multirow[t]{2}{*}{ ART regimen } & First-line & $3.90(0.41)$ & 0.59 & $0.18,0.99$ & $<0.005$ & 0.12 & $0.03,0.20$ & $<0.008$ \\
\hline & Second-line & $3.76(0.45)$ & Reference & Reference & & Reference & Reference & \\
\hline \multirow[t]{4}{*}{ Current CD4 count (last 6 months) } & $<200$ & $3.85(0.45)$ & Reference & Reference & & Reference & Reference & \\
\hline & 200-349 & $3.88(0.37)$ & 0.34 & $-0.315,0.99$ & 0.307 & -0.01 & $-0.14,0.13$ & 0.937 \\
\hline & $350-499$ & $3.94(0.38)$ & 0.58 & $-0.042,1.20$ & 0.067 & 0.06 & $-0.07,0.19$ & 0.343 \\
\hline & $>500$ & $3.83(0.43)$ & 0.16 & $-0.40,0.72$ & 0.575 & 0.01 & $-0.11,0.13$ & 0.865 \\
\hline \multirow[t]{3}{*}{ Duration of ART treatment in years } & $1-5$ & $3.83(0.49)$ & Reference & & & Reference & Reference & \\
\hline & $6-10$ & $3.91(0.41)$ & 0.35 & $-0.14,0.85$ & 0.157 & 0.12 & $0.02,0.22$ & 0.022 \\
\hline & 11 and above & $3.84(0.41)$ & 0.05 & $-0.42,0.52$ & 0.835 & -0.01 & $-0.11,0.10$ & 0.931 \\
\hline \multirow[t]{3}{*}{ Perceived social support } & Low support & $3.38(0.62)$ & Reference & Reference & & Reference & Reference & \\
\hline & Moderate support & $3.68(0.36)$ & 0.90 & $0.27,1.54$ & 0.006 & 0.18 & $0.04,0.33$ & 0.014 \\
\hline & High support & $3.86(0.42)$ & 2.19 & $1.59,2.80$ & $<0.001$ & 0.43 & $0.29,0.57$ & $<0.001$ \\
\hline \multirow[t]{2}{*}{ Functional disability } & No & $4.01(0.33)$ & 1.42 & $1.08,1.75$ & $<0.001$ & 0.29 & $0.21,0.36$ & $<0.001$ \\
\hline & Yes & $3.64(0.47)$ & Reference & Reference & & Reference & Reference & \\
\hline
\end{tabular}

NOTE: First-line regimen is the use of first choice antiviral drugs and a switch to second-line regimen is recommended when there is treatment failure with firstline treatments. ${ }^{a}$ not included in the final model of analysis; ART antiretroviral therapy

need to integrate mental health interventions with existing HIV care as MDD has been found to be one of the major barriers to the global agenda to end the HIV epidemic specially in SSA countries [4-6].

The observed relationship between MDD and overall QoL was consistent with previous findings in HIV populations [69, 71-73]. Evidence shows that MDD consistently leads to worse health outcomes in PLHWA not solely due to difference in adherence to ART but may also be due to direct effect of MDD on physiological functioning [1]. Firstly, MDD can affect QoL by interfering with immune system functioning. Secondly, MDD affects positive thoughts for change that can lead to lower adherence to ART. Thirdly, the relationship between MDD and poor QoL can also explained by indirect effects of MDD on QoL such as financial insecurity, unemployment and financial dependency on others [8]. The overall findings of this study indicated that addressing MDD should be a priority to facilitate recovery and functioning of PLWHA. A recent systematic review and meta-analysis of RCTs found that psychological treatments enhance immune system functioning and are 
Table 5 Linear regression: association of socio-demographic and clinical factors with the domains of quality of life among people living with HIV/AIDS in Felege-Hiwot Referral Hospital, Northwest, Ethiopia, ( $=391)$

\begin{tabular}{|c|c|c|c|c|c|c|c|}
\hline \multicolumn{2}{|c|}{ Sociodemographic and clinical factors } & \multirow{2}{*}{$\begin{array}{l}\text { Physical } \\
\beta(95 \% \mathrm{Cl}) \\
\text { Reference }\end{array}$} & \multirow{2}{*}{$\begin{array}{l}\text { Psychological } \\
\beta(95 \% \mathrm{Cl}) \\
\text { Reference }\end{array}$} & \multirow{2}{*}{$\begin{array}{l}\text { Independence } \\
\beta(95 \% \mathrm{Cl}) \\
\text { Reference }\end{array}$} & \multirow{2}{*}{$\begin{array}{l}\text { Social } \\
\beta(95 \% \mathrm{Cl}) \\
\text { Reference }\end{array}$} & \multirow{2}{*}{$\begin{array}{l}\text { Environmental } \\
\beta(95 \% \mathrm{Cl}) \\
\text { Reference }\end{array}$} & \multirow{2}{*}{$\begin{array}{l}\text { Spiritual } \\
\beta(95 \% \mathrm{Cl}) \\
\text { Reference }\end{array}$} \\
\hline Age & $18-29$ & & & & & & \\
\hline & $30-39$ & $\begin{array}{l}-0.05(-0.22 \\
0.11)\end{array}$ & $\begin{array}{l}0.07(-0.09 \\
0.23)\end{array}$ & $\begin{array}{l}-0.01(-0.16 \\
0.15)\end{array}$ & $\begin{array}{l}0.12(-0.03 \\
0.28)\end{array}$ & $\begin{array}{l}0.18(0.01, \\
0.37)\end{array}$ & $\begin{array}{l}0.07(-0.07 \\
0.20)\end{array}$ \\
\hline & $40-49$ & $\begin{array}{l}-0.10(-0.27 \\
0.08)\end{array}$ & $\begin{array}{l}0.10(-0.07 \\
0.27)\end{array}$ & $\begin{array}{l}-0.03(-0.20 \\
0.14)\end{array}$ & $\begin{array}{l}0.10(0.07 \\
0.27)\end{array}$ & $\begin{array}{l}0.26(0.06, \\
0.46)\end{array}$ & $\begin{array}{l}0.08(-0.06 \\
0.23)\end{array}$ \\
\hline & $50+$ & $\begin{array}{l}-0.11(-0.32 \\
0.09)\end{array}$ & $\begin{array}{l}0.16(-0.05 \\
0.36)\end{array}$ & $\begin{array}{l}-0.09(-0.30 \\
0.09)\end{array}$ & $\begin{array}{l}0.14(-0.05 \\
0.33)\end{array}$ & $\begin{array}{l}0.23(0.02, \\
0.46)\end{array}$ & $\begin{array}{l}0.11(-0.05 \\
0.28)\end{array}$ \\
\hline \multirow[t]{3}{*}{ Marital status } & $\begin{array}{l}\text { Married/ } \\
\text { relationship }\end{array}$ & Reference & Reference & Reference & Reference & Reference & Reference \\
\hline & Single & $\begin{array}{l}-0.10(-0.27 \\
0.07)\end{array}$ & $\begin{array}{l}0.01(-0.16 \\
0.17)\end{array}$ & $\begin{array}{l}-0.09(-0.25 \\
0.07)\end{array}$ & $\begin{array}{l}-0.16(-0.32 \\
0.01)\end{array}$ & $\begin{array}{l}0.18(-0.02 \\
0.37)\end{array}$ & $\begin{array}{l}-0.09(-0.23 \\
0.05)\end{array}$ \\
\hline & $\begin{array}{l}\text { Divorced/ } \\
\text { widowed }\end{array}$ & $\begin{array}{l}0.01(-0.10 \\
0.13)\end{array}$ & $\begin{array}{l}0.07(-0.04 \\
0.18)\end{array}$ & $\begin{array}{l}0.06(-0.05 \\
0.17)\end{array}$ & $\begin{array}{l}-0.08(-0.19 \\
0.03)\end{array}$ & $\begin{array}{l}0.07(-0.07 \\
0.20)\end{array}$ & $\begin{array}{l}-0.05(-0.14 \\
0.05)\end{array}$ \\
\hline \multirow[t]{4}{*}{ Educational status } & Illiterate & Reference & Reference & Reference & Reference & Reference & Reference \\
\hline & $\begin{array}{l}\text { Primary } \\
\text { education }\end{array}$ & $\begin{array}{l}0.20(0.07 \\
0.33)\end{array}$ & $\begin{array}{l}0.17(0.04, \\
0.30)\end{array}$ & $\begin{array}{l}0.22(0.09 \\
0.35)\end{array}$ & $\begin{array}{l}0.11(-0.01 \\
0.24)\end{array}$ & $\begin{array}{l}0.12(-0.03 \\
0.28)\end{array}$ & $\begin{array}{l}0.12(0.01, \\
0.22)\end{array}$ \\
\hline & $\begin{array}{l}\text { Secondary } \\
\text { education }\end{array}$ & $\begin{array}{l}0.21(0.06, \\
0.35)\end{array}$ & $\begin{array}{l}0.22(0.07 \\
0.36)\end{array}$ & $\begin{array}{l}0.21(0.07 \\
0.35)\end{array}$ & $\begin{array}{l}0.13(-0.01 \\
0.27)\end{array}$ & $\begin{array}{l}0.31(0.14, \\
0.48)\end{array}$ & $\begin{array}{l}0.13(0.01 \\
0.25)\end{array}$ \\
\hline & $\begin{array}{l}\text { Tertiary } \\
\text { education }\end{array}$ & $\begin{array}{l}0.27(0.06, \\
0.48)\end{array}$ & $\begin{array}{l}0.51(0.30 \\
0.72)\end{array}$ & $\begin{array}{l}0.35(0.15 \\
0.56)\end{array}$ & $\begin{array}{l}0.16(-0.04 \\
0.37)\end{array}$ & $\begin{array}{l}0.33(0.10 \\
0.57)\end{array}$ & $\begin{array}{l}0.23(0.06 \\
0.41)\end{array}$ \\
\hline \multirow[t]{3}{*}{ Employment status } & Public servant & $\begin{array}{l}-0.08(-0.26 \\
0.09)\end{array}$ & $\begin{array}{l}-0.09(-0.26 \\
0.09)\end{array}$ & $\begin{array}{l}0.01(-0.16 \\
0.18)\end{array}$ & $\begin{array}{l}-0.01(-0.17 \\
0.16)\end{array}$ & $\begin{array}{l}-0.04(-0.23 \\
0.16)\end{array}$ & $\begin{array}{l}-0.09(-0.23 \\
0.06)\end{array}$ \\
\hline & Self employed & $\begin{array}{l}-0.04(-0.16 \\
0.08)\end{array}$ & $\begin{array}{l}0.17(0.05 \\
0.29)\end{array}$ & $\begin{array}{l}0.07(-0.04 \\
0.19)\end{array}$ & $\begin{array}{l}-0.11(-0.22 \\
0.01)\end{array}$ & $\begin{array}{l}-0.01(-0.14 \\
0.13)\end{array}$ & $\begin{array}{l}-0.07(-0.17 \\
0.02)\end{array}$ \\
\hline & Unemployed & Reference & Reference & Reference & Reference & Reference & Reference \\
\hline \multirow[t]{3}{*}{ Perceived social support } & Low support & Reference & Reference & Reference & Reference & Reference & Reference \\
\hline & $\begin{array}{l}\text { Moderate } \\
\text { support }\end{array}$ & $\begin{array}{l}0.15(-0.05 \\
0.34)\end{array}$ & $\begin{array}{l}0.34(0.15 \\
0.53)\end{array}$ & $\begin{array}{l}0.23(0.05 \\
0.42)\end{array}$ & $\begin{array}{l}0.10(-0.08, \\
0.29)\end{array}$ & $\begin{array}{l}0.11(-0.13 \\
0.34)\end{array}$ & $\begin{array}{l}0.19(0.03 \\
0.35)\end{array}$ \\
\hline & High support & $\begin{array}{l}0.25(0.06 \\
0.44)\end{array}$ & $\begin{array}{l}0.60(0.42 \\
0.79)\end{array}$ & $\begin{array}{l}0.37(0.19 \\
0.56)\end{array}$ & $\begin{array}{l}0.68(0.50 \\
0.87)\end{array}$ & $\begin{array}{l}0.45(0.22 \\
0.68)\end{array}$ & $\begin{array}{l}0.28(0.13, \\
0.44)\end{array}$ \\
\hline \multirow[t]{2}{*}{ ART regimen } & First-line & $\begin{array}{l}0.15(0.04 \\
0.27)\end{array}$ & $\begin{array}{l}0.19(0.07 \\
0.30)\end{array}$ & $\begin{array}{l}0.11(0.01, \\
0.23)\end{array}$ & $\begin{array}{l}0.10(-0.01 \\
0.21)\end{array}$ & $\begin{array}{l}0.08(-0.05 \\
0.22)\end{array}$ & $\begin{array}{l}0.08(-0.02 \\
0.17)\end{array}$ \\
\hline & Second-line & Reference & Reference & Reference & Reference & Reference & Reference \\
\hline \multirow[t]{2}{*}{ Functional Disability } & No & $\begin{array}{l}0.39(0.28 \\
0.49)\end{array}$ & $\begin{array}{l}0.55(0.44, \\
0.66)\end{array}$ & $\begin{array}{l}0.35(0.25 \\
0.45)\end{array}$ & $\begin{array}{l}0.25(0.15 \\
0.35)\end{array}$ & $\begin{array}{l}0.10(-0.02, \\
0.22)\end{array}$ & $\begin{array}{l}0.17(0.08, \\
0.26)\end{array}$ \\
\hline & Yes & Reference & Reference & Reference & Reference & Reference & Reference \\
\hline \multirow{4}{*}{$\begin{array}{l}\text { Current CD4 count (last } 6 \\
\text { months) }\end{array}$} & $<200$ & Reference & Reference & Reference & Reference & Reference & Reference \\
\hline & 200-349 & $\begin{array}{l}-0.07(-0.27 \\
0.12)\end{array}$ & $\begin{array}{l}0.07(-0.12 \\
0.26)\end{array}$ & $\begin{array}{l}-0.03(-0.21 \\
0.16)\end{array}$ & $\begin{array}{l}0.04(-0.14 \\
0.22)\end{array}$ & $\begin{array}{l}-0.08(-0.30 \\
0.15)\end{array}$ & $\begin{array}{l}0.14(-0.02 \\
0.30)\end{array}$ \\
\hline & $350-499$ & $\begin{array}{l}0.03(-0.16 \\
0.21)\end{array}$ & $\begin{array}{l}0.08(-0.10 \\
0.26)\end{array}$ & $\begin{array}{l}0.07(-0.10 \\
0.25)\end{array}$ & $\begin{array}{l}0.04(-0.14 \\
0.21)\end{array}$ & $\begin{array}{l}-0.03(-0.24 \\
0.18)\end{array}$ & $\begin{array}{l}0.13(-0.02 \\
0.28)\end{array}$ \\
\hline & $>500$ & $\begin{array}{l}0.01(-0.17 \\
0.17)\end{array}$ & $\begin{array}{l}0.01(-0.15 \\
0.18)\end{array}$ & $\begin{array}{l}-0.04(-0.20 \\
0.12)\end{array}$ & $\begin{array}{l}0.03(-0.13 \\
0.19)\end{array}$ & $\begin{array}{l}-0.05(-0.24 \\
0.15)\end{array}$ & $\begin{array}{l}0.05(-0.09 \\
0.19)\end{array}$ \\
\hline \multirow{3}{*}{$\begin{array}{l}\text { ART treatment duration in } \\
\text { years }\end{array}$} & $1-5$ & Reference & Reference & Reference & Reference & Reference & Reference \\
\hline & $6-10$ & $\begin{array}{l}0.17(0.03, \\
0.32)\end{array}$ & $\begin{array}{l}0.12(-0.02, \\
0.27)\end{array}$ & $\begin{array}{l}0.13(-0.01 \\
0.27)\end{array}$ & $\begin{array}{l}0.05(-0.09 \\
0.19)\end{array}$ & $\begin{array}{l}0.01(-0.15 \\
0.18)\end{array}$ & $\begin{array}{l}0.17(0.05 \\
0.29)\end{array}$ \\
\hline & $11+$ & $\begin{array}{l}0.03(-0.11 \\
0.18)\end{array}$ & $\begin{array}{l}0.03(-0.12 \\
0.17)\end{array}$ & $\begin{array}{l}-0.05(-0.19 \\
0.09)\end{array}$ & $\begin{array}{l}-0.04(-0.09 \\
0.19)\end{array}$ & $\begin{array}{l}-0.14(-0.30 \\
0.03)\end{array}$ & $\begin{array}{l}0.04(-0.08 \\
0.16)\end{array}$ \\
\hline
\end{tabular}

The results in this table were identified in multivariate linear regression. All variables associated with overall QoL at $>0.2$ were controlled multivariate analyses with each domain of QoL. First-line regimen is the use of first choice antiviral drugs and a switch to second-line regimen is recommended when there is treatment failure with first-line treatments. ART antiretroviral therapy 
Table 6 Generalised linear model univariate analysis: association of major depressive disorder and adherence to antiretroviral therapy with the overall quality of life after adjusting for socio-demographic and clinical factors among people living with HIV/AIDS in Felege-Hiwot Referral Hospital, Northwest Ethiopia, $N=391$

\begin{tabular}{|c|c|c|c|c|c|}
\hline \multirow[t]{2}{*}{ Covariates } & & \multirow{2}{*}{$\begin{array}{l}\text { Mean } \\
\text { (SD) }\end{array}$} & \multicolumn{3}{|c|}{ Adjusted linear regression } \\
\hline & & & Coefficient & $95 \% \mathrm{Cl}$ & $P$ value \\
\hline \multirow[t]{2}{*}{ Major depressive disorder } & No & $3.99(0.33)$ & Reference & Reference & \\
\hline & Yes & $3.59(0.47)$ & -0.06 & $0.89,0.99$ & 0.047 \\
\hline \multirow[t]{2}{*}{ Adherence to ART } & High adherence & $3.86(0.40)$ & Reference & & \\
\hline & Low adherence & $3.73(0.46)$ & -0.03 & $0.93,1.02$ & 0.277 \\
\hline MDD*Adherence to ART & & & 0.01 & $0.94,1.07$ & 0.866 \\
\hline
\end{tabular}

NOTE: All variables associated with overall QoL at $>0.05$ were controlled for in this model (age, marital status, educational status, employment status, antiretroviral therapy (ART) regimen, CD4 count, duration of ART treatment, perceived social support and functional disability). ART: antiretroviral therapy

viable for improving immune function [75]. Therefore, we recommend the use of psychological treatments for treatment of depressive symptoms and to improve immune functioning that could help to improve overall QoL of PLWHA. We recommend that mental health researchers develop evidence-based psychological treatments that are appropriate for PLWHA to manage depression, and to improve adherence to ART and overall quality of life of PLWHA. Furthermore, we believe that this study could have several implications for health care providers and policy makers to consider mental health conditions as a priority and to act accordingly. Specifically, routine screening services for depression and other mental disorders should be established at ART clinics and mental health services integrated with HIV care services in Ethiopia.

A major strength of this study was the use of instruments validated in Ethiopia. However, it has also several limitations. Firstly, it is a cross-sectional study that doesn't allow us to identify causal relationships between independent and outcome variables. Secondly, the use of a self-report measure to assess adherence to ART may not be the right approach and future studies should consider alternative approaches. Thirdly, readers should note that suboptimal adherence to ART was defined narrowly as skipping one or more doses of ART medications. Fourth, there may have been recall bias in the manner in which study participants shared their information.

\section{Conclusion}

This study indicates that both MDD and QoL have a strong relationship with functional disability among PLWHA in Northwest Ethiopia. The strong relationship between MDD and QoL indicates the need to integrate feasible, acceptable and evidence-based mental health interventions within the existing HIV care services to improve the overall QoL of PLWHA. We recommend future studies to investigate causal relationships of MDD, adherence to ART and QoL of PLWHA to better understand priority areas for intervention.
Abbreviations

ART: Antiretroviral therapy; MDD: Major depressive disorder; PLWHA: People living with HIV/AIDS; QoL: Quality of life

\section{Acknowledgments}

The authors would like to thank the University of Cape Town and the College of Health Sciences, Bahir Dar University.

\section{Authors' contributions}

$B A, M S, C L$ conceptualized the study. BA drafted the manuscript, and MS, CL, FA and EG revised the manuscript. BA and FA coordinated and supervised data acquisition. EG contributed in selecting methods of analysis, and checked the interpretations of the results. All authors participated in development of the study and write up of the manuscript. All author(s) read and approved the final manuscript.

\section{Funding}

This work was supported through African Mental health research Initiative (AMARI) as part of the DELTAS Africa Initiative [DEL-15-01]. The DELTAS Africa Initiative is an independent funding scheme of the African Academy of Sciences (AAS)'s Alliance for Accelerating Excellence in Science in Africa (AESA) and supported by the New Partnership for Africa's Development Planning and Coordinating Agency (NEPAD Agency) with funding from the Wellcome Trust [DEL-15-01] and the UK government. The views expressed in this publication are those of the author(s) and not necessarily those of AAS, NEPAD Agency, Wellcome Trust or the UK government.

The funders had no role in study design, data collection, analysis,

interpretation of the data, in writing the manuscript and decision to publish.

\section{Availability of data and materials \\ Not applicable.}

\section{Ethics approval and consent to participate}

Ethical approval was obtained from the University of Cape Town's Human Research Ethics Committee (HREC reference No. 653/2018) from Bahir Dar University College of Medicine and Health Sciences' Ethics Committee (reference No. 007/2018). All study participants signed a written informed consent.

\section{Competing interests}

The authors declare that they have no competing interests.

\section{Author details}

${ }^{1}$ Alan J Flisher Centre for Public Mental Health, Department of Psychiatry and Mental Health, University of Cape Town, Cape Town, South Africa. ${ }^{2}$ Centre for Global Mental Health, Department of Health Services and Population Research, King's Global Health Institute, Institute of Psychiatry, Psychology and Neuroscience, King's College London, London, UK. ${ }^{3}$ School of Public Health, College of medicine and Health Sciences, Bahir Dar University, Bahir Dar, Ethiopia. ${ }^{4}$ Department of Psychiatry, College of Health Sciences, Addis Ababa University, Addis Ababa, Ethiopia. 
Received: 22 May 2020 Accepted: 10 September 2020 Published online: 24 September 2020

\section{References}

1. Hartzell JD, Janke IE, Weintrob AC. Impact of depression on HIV outcomes in the HAART era. J Antimicrob Chemother. 2008;62(2):246-55.

2. Remien RH, Stirratt MJ, Nguyen N, Robbins RN, Pala AN, Mellins CA. Mental health and HIV/AIDS: the need for an integrated response. AIDS (London, England). 2019;33(9):1411-20

3. Olatunji BO, Mimiaga MJ, O'Cleirigh C, Safren SA. Review of treatment studies of depression in HIV. Top HIV Med. 2006;14(3):112-24.

4. Kulisewa K, Stockton MA, Hosseinipour MC, Gaynes BN, Mphonda S, Udedi $\mathrm{MM}$, et al. The role of depression screening and treatment in achieving the UNAIDS 90-90-90 goals in sub-Saharan Africa. AIDS Behav. 2019;23(Suppl 2): 153-61.

5. UNAIDS. 90-90-90 An ambitious treatment target to help end the AIDS epidemic. Joint United Nations Programme on HIV/AIDS 2014. https://www. unaids.org/sites/default/files/media_asset/90-90-90_en.pdf. Accessed 14 Sept 2020

6. Abas M, Ali GC, Nakimuli-Mpungu E, Chibanda D. Depression in people living with HIV in sub-Saharan Africa: time to act. Tropical Med Int Health. 2014;19(12):1392-6.

7. Wang T, Fu H, Kaminga AC, Li Z, Guo G, Chen L, et al. Prevalence of depression or depressive symptoms among people living with HIV/AIDS in China: a systematic review and meta-analysis. BMC psychiatry. 2018;18(1): 160.

8. Brandt R. The mental health of people living with HIV/AIDS in Africa: a systematic review. African J AIDS Res. 2009;8(2):123-33.

9. Cruess DG, Petitto JM, Leserman J, Douglas SD, Gettes DR, Ten Have TR, et al. Depression and HIV infection: impact on immune function and disease progression. CNS Spectrums. 2003;8(1):52-8.

10. Bernard C, Dabis F, de Rekeneire N. Prevalence and factors associated with depression in people living with HIV in sub-Saharan Africa: a systematic review and meta-analysis. PLoS One. 2017;12(8):e0181960.

11. Ayano G, Solomon M, Abraha M. A systematic review and meta-analysis of epidemiology of depression in people living with HIV in East Africa. BMC Psychiatry. 2018;18(1):254.

12. Amare T, Getinet W, Shumet S, Asrat B. Prevalence and associated factors of depression among PLHIV in Ethiopia: systematic review and meta-analysis, 2017. AIDS Res Treat. 2018;2018:1-9

13. Bitew T. Prevalence and Risk Factors of Depression in Ethiopia: A Review. Ethiopian J Health Sci. 2014;24(2)

14. Rueda S, Mitra S, Chen S, Gogolishvili D, Globerman J, Chambers L, et al. Examining the associations between HIV-related stigma and health outcomes in people living with HIV/AIDS: a series of meta-analyses. BMJ Open. 2016;6(7):e011453.

15. Cluver L, Gardner F, Operario D. Poverty and psychological health among AIDS-orphaned children in Cape Town. South Africa AIDS Care. 2009;21(6): 732-41.

16. Lachman JM, Cluver LD, Boyes ME, Kuo C, Casale M. Positive parenting for positive parents: HIV/AIDS, poverty, caregiver depression, child behavior, and parenting in South Africa. AIDS Care. 2014;26(3):304-13.

17. Nanni MG, Caruso R, Mitchell AJ, Meggiolaro E, Grassi L. Depression in HIV infected patients: a review. Curr Psychiatry Rep. 2015:17(1):530.

18. Arseniou S, Arvaniti A, Samakouri M. HIV infection and depression. Psychiatry Clin Neurosci. 2014;68(2):96-109.

19. Rivera-Rivera Y, Vázquez-Santiago FJ, Albino E, Sánchez MD, Rivera-Amill V. Impact of Depression and Inflammation on the Progressionof HIV Disease. J Clin Cell Immunol. 2016;7(3):423. https://doi.org/10.4172/2155-9899.1000423.

20. Degroote S, Vogelaers D, DM. V. What determines health-related quality of life among people living with HIV: an updated review of the literature. Arch Public Health. 2014;72(40).

21. Sin NL, DiMatteo MR. Depression treatment enhances adherence to antiretroviral therapy: a meta-analysis. Ann Behav Med. 2014;47(3):259-69.

22. Uthman OA, Magidson JF, Safren SA, Nachega JB. Depression and adherence to antiretroviral therapy in low-, middle- and high-income countries: a systematic review and meta-analysis. Curr HIV/AIDS Rep. 2014; 11(3):291-307

23. Tao J, Qian HZ, Kipp AM, Ruan Y, Shepherd BE, Amico KR, et al. Effects of depression and anxiety on antiretroviral therapy adherence among newly diagnosed HIV-infected Chinese MSM. AIDS (London, England). 2017;31(3): 401-6.

24. Hudelson C, Cluver L. Factors associated with adherence to antiretroviral therapy among adolescents living with HIV/AIDS in low- and middleincome countries: a systematic review. AIDS Care. 2015;27(7):805-16.

25. Rubin HL, and, Maki MP. HIV, depression, and cognitive impairment in the era of effective antiretroviral therapy. Current HIV/AIDS reports 2019 DOI: https://doi.org/10.1007/s11904-019-00421-0.

26. Collins PY, Holman AR, Freeman MC, Patel V. What is the relevance of mental health to HIV/AIDS care and treatment programs in developing countries? A systematic review. AIDS (London, England). 2006;20(12):157182.

27. Sikkema KJ, Dennis AC, Watt MH, Choi KW, Yemeke TT, Joska JA. Improving mental health among people living with HIV: a review of intervention trials in low- and middle-income countries. Glob Ment Health (Camb). 2015;2:e19. https://doi.org/10.1017/gmh.2015.17.

28. Asrat B, Schneider M, Ambaw F, Lund C. Effectiveness of psychological treatments for depressive symptoms among people living with HIV/AIDS in low- and middle-income countries: a systematic review and meta-analysis. J Affect Disord. 2020;270:174-87.

29. Cooper V, Clatworthy J, Harding R, Whetham J, Emerge C. Measuring quality of life among people living with HIV: a systematic review of reviews. Health Qual Life Outcomes. 2017;15(1):220.

30. Pietersma S, de Vries M, van den Akker-van Marle ME. Domains of quality of life: results of a three-stage Delphi consensus procedure among patients, family of patients, clinicians, scientists and the general public. Qual Life Res. 2014;23(5):1543-56.

31. Lund C, Waruguru M, Kingori J, Kippen-Wood S, Breuer E, Mannarath S, et al. Outcomes of the mental health and development model in rural Kenya: a 2-year prospective cohort intervention study. Int Health. 2013;5(1):43-50.

32. Alemayehu M, Wubshet M, Mesfin N, Tamiru A, Gebayehu A. Health-related quality of life of HIV infected adults with and without visceral Leishmaniasis in Northwest Ethiopia. Health Qual Life Outcomes. 2017;15(1):65.

33. Primeau MM, Avellaneda V, Musselman D, Jean SG, Illa L. Treatment of depression in individuals living with HIV/AIDS. Psychosomatics. 2013;54:33644.

34. Mayston R, Kinyanda E, Chishinga N, Prince M, Patel V. Mental disorder and the outcome of HIV/AIDS in low-income and middle-income countries: a systematic review. AIDS (London, England). 2012;26(Suppl 2):S117-35.

35. Moore RC, Fazeli PL, Jeste DV, Moore DJ, Grant I, Woods SP, et al. Successful cognitive aging and health-related quality of life in younger and older adults infected with HIV. AIDS Behav. 2014;18(6):1186-97.

36. Shumye S, Belayneh Z, Mengistu N. Health related quality of life and its correlates among people with depression attending outpatient department in Ethiopia: a cross sectional study. Health Qual Life Outcomes. 2019;17(1): 169.

37. Reis EA. Symptoms of depression and quality of life of people living with HIV/AIDS. Rev Latino-Am Enfermagem. 2011;19(4):874-81.

38. Tesfaye M, Kaestel P, Olsen MF, Girma T, Yilma D, Abdissa A, et al. Food insecurity, mental health and quality of life among people living with HIV commencing antiretroviral treatment in Ethiopia: a cross-sectional study. Health Qual Life Outcomes. 2016;14:37.

39. Duggal S, Chugh TD, Duggal AK. HIV and malnutrition: effects on immune system. Clin Develop Immunol. 2012;2012:784740.

40. Hong S, Banks WA. Role of the immune system in HIV-associated neuroinflammation and neurocognitive implications. Brain Behav Immun. 2015:45:1-12.

41. Alemayehu M, Wubshet M, Mesfin N, Gebayehu A. Effect of health care on quality of life among human immunodeficiency virus infected adults with and without visceral Leishmaniasis in Northwest Ethiopia: a longitudinal follow-up study. Am J Trop Med Hyg. 2018;98(3):747-52.

42. Asrat B, Lund C, Ambaw F, Schneider M. Adaptation of the WHO group interpersonal therapy for people living with HIV/AIDS in Northwest Ethiopia: A qualitative study. PLoS ONE. 2020;15(8):e0238321. https://doi.org/10.1371/ journal.pone.0238321.

43. Sheehan DV. Mini International Neuropsychiatric Interview English version 7. 0.2 for DSM-5. University of South Florida College of Medicine; 2016.

44. Sheehan DV, Lecrubier IY, Sheehan $\mathrm{KH}$, al e. The validity of the MINI international neuropsychiatric interview (MINI) according to the SCID-P and its reliability. Eur Psychiatry 1997;12:232-241. 
45. Hanlon C, Medhin G, Selamu M, Breuer E, Worku B, Hailemariam M, et al. Validity of brief screening questionnaires to detect depression in primary care in Ethiopia. J Affect Disord. 2015;186:32-9.

46. Tesfaye M, Olsen MF, Medhin G, Friis H, Hanlon C, Holm L. Adaptation and validation of the short version WHOQOL-HIV in Ethiopia. Int J Ment Health Syst. 2016;10:29.

47. Pednekar PP, Agh T, Malmenas M, Raval AD, Bennett BM, Borah BJ, et al. Methods for measuring multiple medication adherence: a systematic review-report of the ISPOR medication adherence and persistence special interest group. Value Health. 2019;22(2):139-56.

48. Achieng L, Musangi $H$, Billingsley $K$, Onguit $S$, Ombegoh E, Bryant L, et al. The use of pill counts as a facilitator of adherence with antiretroviral therapy in resource limited settings. PLoS One. 2013;8(12):e67259.

49. Habtamu K, Alem A, Medhin G, Fekadu A, Dewey M, Prince M, et al. Validation of the World Health Organization disability assessment schedule in people with severe mental disorders in rural Ethiopia. Health Qual Life Outcomes. 2017;15(1):64.

50. Canty-Mitchell J, Zimet GD. Psychometric properties of the Multidimensional Scale of Perceived Social Support in urban adolescents. Am JCommunity Psychol. 2000;28(3):391-400. https://doi.org/10.1023/A: 1005109522457

51. Dambi JM, Corten L, Chiwaridzo M, et al. A systematic review of the psychometric properties of the cross-cultural translations and adaptations of the Multidimensional Perceived Social Support Scale (MSPSS). Health Qual Life Outcomes. 2018;16:80. https://doi.org/10.1186/s12955-018-0912-0.

52. Wang $Y$, Wan Q, Huang Z, Huang L, Kong F. Psychometric properties of multi-dimensional scale of perceived social support in Chinese parents of children with cerebral palsy. Front Psychol. 2017:8:2020.

53. Stewart RC, Umar E, Tomenson B, Creed F. Validation of the multidimensional scale of perceived social support (MSPSS) and the relationship between social support, intimate partner violence and antenatal depression in Malawi. BMC Psychiatry. 2014;14:180.

54. Nakigudde J, Musisi S, Ehnvall A, Airaksinen E, and, Agren H. Adaptation of the multidimensional scale of perceived social support in a Ugandan setting. Afr Health Sci 2009;9(Suppl 1):S35-41.

55. Zimet GDDN, Zimet SG, Farley GK. The multidimensional scale of perceived social support. J Pers Assess. 1988;52:30-41.

56. Zimet G. Multidimensional Scale of Perceived Social Support (MSPSS) - Scale Items and Scoring Information Duke University. 2016;https://www. researchgate.net/publication/311534896_Multidimensional_Scale_of_ Perceived_Social_Support_MSPSS_-_Scale_Items_and_Scoring_Information.

57. Odense Denmark EA, 2000-2020. EpiData software. Available from https:// www.epidatadk/downloadphp. 2019.

58. Corp. I. IBM SPSS Statistics for Windows, . Version 260. Armonk, NY: IBM Corp. Released; 2019.

59. Zou G. A modified Poisson regression approach to prospective studies with binary data. Am J Epidemiol. 2004;159:702-6.

60. Girum T, Wasie A, Lentiro K, Muktar E, Shumbej T, Difer M, et al. Gender disparity in epidemiological trend of HIV/AIDS infection and treatment in Ethiopia. Archives Public Health = Archives belges de sante publique. 2018; 76:51

61. Simoni JM, Safren SA, Manhart LE, Lyda K, Grossman Cl, Rao D, et al. Challenges in addressing depression in HIV research: assessment, cultural context, and methods. AIDS Behav. 2010;15(2):376-88.

62. Wang J, Mann F, Lloyd-Evans B, Ma R, Johnson S. Associations between loneliness and perceived social support and outcomes of mental health problems: a systematic review. BMC Psychiatry. 2018;18(1):156.

63. Gariepy G, Honkaniemi H, Quesnel-Vallee A. Social support and protection from depression: systematic review of current findings in Western countries. Br J Psychiatry. 2016;209(4):284-93.

64. Ren P, Qin X, Zhang Y, Zhang R. Is social support a cause or consequence of depression? A Longitudinal Study of Adolescents Front Psychol. 2018;9: 1634.

65. Lipsitz JD, Markowitz JC. Mechanisms of change in interpersonal therapy (IPT). Clin Psychol Rev. 2013;33(8):1134-47.

66. Noh JW, Kwon YD, Park J, Oh IH, Kim J. Relationship between physical disability and depression by gender: a panel regression model. PLoS One. 2016;11(11):e0166238

67. Ormel J, Rijsdijk VF, Sullivan M, Sonderen V, Kempen IJMG. Temporal and reciprocal relationship between $I A D L / A D L$ disability and depressive symptoms in late life. J Gerontol Psychol Sci. 2002;57B(4):338-48.
68. Lund C, Breen A, Flisher AJ, Kakuma R, Corrigall J, Joska JA, et al. Poverty and common mental disorders in low and middle income countries: A systematic review. Soc Sci Med (1982). 2010;71(3):517-28.

69. Passos SM, Souza LD. An evaluation of quality of life and its determinants among people living with HIV/AIDS from southern Brazil. Cadernos de saude publica. 2015;31(4):800-14

70. Liping M, Peng X, Haijiang L, Lahong J, Fan L. Quality of life of people living with HIV/AIDS: a cross-sectional study in Zhejiang Province. China PLoS One. 2015;10(8):e0135705.

71. Mutabazi-Mwesigire D, Katamba A, Martin F, Seeley J, Wu AW. Factors that affect quality of life among people living with HIV attending an Urban Clinic in Uganda: a cohort study. PLoS One. 2015;10(6):e0126810.

72. Degroote S, Vogelaers D, Vandijck DM. What determines health-related quality of life among people living with HIV: an updated review of the literature. Archives of public health $=$ Archives belges de sante publique 2014;72(1):40

73. Nobre N, Pereira M, Roine RP, Sintonen H, Sutinen J. Factors associated with the quality of life of people living with HIV in Finland. AIDS Care. 2017;29(8): 1074-8..

74. Oguntibeju OO. Quality of life of people living with HIV and AIDS and antiretroviral therapy. Hiv/Aids. 2012;4:117-24

75. Shields GS, Spahr CM, Slavich GM. Psychosocial Interventions and Immune System Function: A Systematic Review and Meta-analysis of Randomized Clinical Trials [published online ahead of print, 2020 Jun 3]. JAMA Psychiatry. 2020;e200431. https://doi.org/10.1001/jamapsychiatry.2020.0431.

\section{Publisher's Note}

Springer Nature remains neutral with regard to jurisdictional claims in published maps and institutional affiliations.

Ready to submit your research? Choose BMC and benefit from:

- fast, convenient online submission

- thorough peer review by experienced researchers in your field

- rapid publication on acceptance

- support for research data, including large and complex data types

- gold Open Access which fosters wider collaboration and increased citations

- maximum visibility for your research: over $100 \mathrm{M}$ website views per year

At BMC, research is always in progress.

Learn more biomedcentral.com/submissions 